\title{
Tumor Necrosis Factor-Induced Neutrophil Adhesion Occurs Via Sphingosine Kinase-1-Dependent Activation of Endothelial $\alpha_{5} \beta_{1}$ Integrin
}

\author{
Wai Y. Sun, ${ }^{*}$ Stuart M. Pitson, ${ }^{* \dagger}$ \\ and Claudine S. Bonder ${ }^{* \neq}$ \\ From the Department of Human Immunology, Centre for \\ Cancer Biology, South Australia Pathology, School of Molecular \\ and Biomedical Science, ${ }^{\dagger}$ and School of Medicine, ${ }^{\ddagger}$ University of \\ Adelaide, Adelaide, South Australia, Australia
}

Leukocyte recruitment plays a major role in the immune response to infectious pathogens, as well as during inflammatory and autoimmune disorders. The process of leukocyte extravasation from the blood requires a complex cascade of adhesive events between the leukocytes and the endothelium, including initial leukocyte rolling, adhesion, and finally transendothelial migration. Current research in this area aims to identify the key leukocyte subsets that initiate a given disease and to identify the trafficking molecule(s) that will most specifically inhibit those cells. Herein we demonstrate that tumor necrosis factor (TNF) $\alpha$ activates the integrin $\alpha_{5} \beta_{1}$ without altering total expression levels of $\beta_{1}$ integrin on human umbilical vein endothelial cells. Moreover, our studies suggest that TNF $\alpha$-induced $\beta_{1}$ activation is dependent on sphingosine kinase-1, but independent of the sphingosine-1-phosphate family of G protein-coupled receptors. We also show, using a parallel plate flow chamber assay, that neutrophil adhesion to TNF $\alpha$ activated endothelium can be attenuated by blocking $\alpha_{5} \beta_{1}$ or its ligand angiopoietin-2. These observations add new complexities that broaden the accepted concept of cellular trafficking with neutrophil adhesion to TNF $\alpha$ activated endothelial cells being sphingosine kinase-1, $\alpha_{5} \beta_{1}$, and angiopoietin-2 dependent. Moreover, this work supports the notion that sphingosine kinase-1 may be the single target required for an effective broad spectrum approach to combat inflammation and immune disorders. (Am J Pathol 2010, 177:436-446; DOI: 10.2353/ajpath.2010.091016)

To fulfill their surveillance function, leukocytes continuously patrol the human body, shuttling back and forth between the blood stream, the lymphatic fluid, secondary lymphoid organs, and peripheral tissues. ${ }^{1}$ Leukocyte recruitment to sites of inflammation is critical for the development and maintenance of the immune response. During injury and pathogen invasion, inflammatory cytokines, such as tumor necrosis factor (TNF) $\alpha$, are released to recruit leukocytes. However, excessive and remaining cytokines at these sites often result in prolonged inflammation, tissue damage, and disease. When leukocytes leave the blood stream, they undergo a sequential adhesion cascade to overcome both the high shear forces within the blood vessel and the tight seal of endothelial cells that line these vessels. The classical paradigm for leukocyte recruitment states that the selectin-family (ie, P-selectin, E-selectin, and L-selectin) uses transient interactions with carbohydrates to initiate tethering and rolling (reviewed in 2). Leukocyte arrest during rolling is rapidly triggered by chemoattractants (eg, chemokines) and is mediated by the binding of leukocyte integrins to immunoglobulin superfamily members, such as vascular and cellular adhesion molecule (VCAM) - 1 and intercellular adhesion molecule (ICAM)-1, expressed by endothelial cells (ECs). This stabilization of the rolling leukocytes to the endothelium enables their emigration from the microvasculature. Undoubtedly, the diversity in selectivity and extent of leukocyte recruitment are regulated by the intrinsic complexity of pro-adhesive signaling networks expressed by the vasculature.

The family of integrins are significant contributors to leukocyte adhesion, with their qualitative and quantitative variations of expression and activation states. In the past

Supported by the Australian National Health and Medical Research Council (NHMRC) Project grant to C.S.B. (430907). C.S.B. is an NHMRC Peter Doherty Training Fellow (278806) and currently holds a Royal Adelaide Hospital Florey Fellowship. S.M.P. is an NHMRC Senior Research Fellow (508098).

Accepted for publication February 26, 2010.

Supplemental material for this article can be found on http://ajp. amjpathol.org.

Address reprint requests to Dr. Claudine S. Bonder, Ph.D., Human Immunology, Centre for Cancer Biology, SA Pathology, Frome Rd, Adelaide, SA 5000, Australia. E-mail: claudine.bonder@health.sa.gov.au. 
decade, new insights have been gained in understanding the combination and activation of the $18 \alpha$ and $8 \beta$ integrin subunit family members, which associate in pairs to form at least $24 \alpha \beta$ receptors (reviewed in 3, 4). Moreover, modulation of integrin ligand affinity is now widely recognized as a crucial step in agonist-induced leukocyte arrest under flow. ${ }^{5}$ Indeed, specific integrin blocking molecules are effective therapeutic strategies in multiple sclerosis and psoriasis as they modulate leukocyte trafficking. ${ }^{6,7}$ However, their inability to provide absolute protection suggests that the precise mechanisms underpinning cellular recruitment remain incompletely understood. ${ }^{8}$

TNF $\alpha$ is one of the most pleiotropic cytokines involved in systemic inflammation and has been implicated in a multitude of pathologies including autoimmune disease, insulin resistance, and cancer (reviewed in 9). A major site for TNF $\alpha$ action is the vascular endothelium where it binds to membrane receptors and instigates a cascade of intracellular signaling events for EC production of cytokines and induction of adhesion molecule expression. $\mathrm{TNF} \alpha$ also stimulates the activation of sphingomyelinase and sphingosine kinase $(S K)-1$, yielding sphingosine-1phosphate (S1P) (reviewed in 10). Although most cells can synthesize S1P, large amounts are present in platelets, ${ }^{11}$ and recent reports have identified erythrocytes as well as vascular endothelium as major contributors of S1P in circulation. ${ }^{12-14} \mathrm{~S} 1 \mathrm{P}$ can act extracellularly through the $G$ protein coupled S1P receptors $\left(\mathrm{S}_{1} \mathrm{P}_{1-5}\right)$. Mature ECs express $\mathrm{S} 1 \mathrm{P}$ receptors $\mathrm{S}_{1} \mathrm{P}_{1-3}$ and these ligand/receptor interactions promote EC survival, migration, proliferation, adherens junction assembly, increased revascularization, and wound healing both in vitro and in vivo (reviewed in 15). However, S1P can also act intracellularly, possibly through histone deacetylases ${ }^{16}$ or other as yet unknown binding partners, where the ablation of receptor signaling through both chemical or genetic mechanisms does not abrogate S1P effects on cell proliferation, $\mathrm{Ca}^{2+}$ mobilization, EC survival, nor the differentiation of endothelial progenitor cells. ${ }^{10,17}$ SK-1 has two functional states, an intrinsic or basal state and an agonist-induced activated state, which requires its phosphorylation and is responsible for its oncogenic properties. ${ }^{18}$ More recently we observed that SK-1 activates $\alpha_{\mathrm{v}} \beta_{3}$ integrin to mediate EC survival signaling pathway via formation of a heterotrimeric complex between SK-1, $\alpha_{\mathrm{v}} \beta_{3}$ and CD31. ${ }^{19}$ In ECs, TNF $\alpha$-induced up-regulation of E-selectin, VCAM-1 and ICAM-1 expression is an SK-1-dependent process. ${ }^{20,21}$ Together, it is tempting to speculate that SK-1 may also contribute to integrin-mediated leukocyte adhesion under shear stress, and as such, act as a master switch for adhesion molecules and thus become a single target for therapeutic intervention.

In this study, we have examined the role of SK-1 in direct leukocyte adhesion under physiologically relevant shear flow. We show that although TNF $\alpha$ stimulation of human umbilical vein endothelial cells (HUVECs) does not alter total $\beta_{1}$ protein levels it significantly increases the formation of $\alpha_{5} \beta_{1}$ (very late antigen -5 ) and promotes angiopoietin (Ang) -2 expression at the EC surface. Fur- thermore, we hypothesize that an active conformation of $\beta_{1}$ integrin exists on these cells as identified by a unique anti- $\beta_{1}$ integrin monoclonal antibody, QE.2E5. This antibody was originally developed by Faull et al ${ }^{22}$ following immunization of mice with lipopolysaccharide-activated HUVECs and binds to a site remote from that of the ligand, as well as other function-modifying $\beta_{1}$ antibodies. Importantly, QE.2E5 is itself without effect on the adhesive, proliferative, and tube-forming capabilities of both untreated and phorbol-12-myristate-13-acetate-treated HUVECs. ${ }^{23}$ This study now proposes a novel mechanism of neutrophil adhesion under shear flow involving TNF $\alpha$ induced $\alpha_{5} \beta_{1}$ activation and Ang-2 expression, which is SK-1-dependent.

\section{Materials and Methods}

\section{Reagents and Antibodies}

Murine monoclonal antibodies directed against $\beta_{1}$ (QE.2E5, 61.2C4, and 58.7H2), VCAM-1 (51.10C9) and E-selectin $(68.5 \mathrm{H} 11)$ were used along with isotype control (23.1F11; gifts, Prof Jennifer Gamble, Centenary Institute, NSW, Australia); $\alpha_{5}$ (P1D6), $\alpha_{2}$ (P1E6), PECAM-1 (M-20), and Ang-2 ( $\mathrm{N}-18)$ antibodies were purchased from Santa Cruz Biotechnology (Santa Cruz, CA); $\alpha_{5} \beta_{1}$ (BMC5 and MAB1999), $\alpha_{v} \beta_{3}$ (LM609), and actin were from Chemicon International Inc (Temecula, CA); VCAM (BBIG-V1) and ICAM (BBIG-I1) were purchased from R\&D Systems, Inc. $(\mathrm{MN}) ; \alpha_{5} \beta_{1}$ (BMC5), ERK (137F5), and P-ERK (197G2) were purchased from Cell Signaling Technologies (Danvers, MA). Secondary anti-goat Alex-555, anti-mouse Alexa-488 and -594 antibodies were purchased from Invitrogen (Carlsbad, CA), and anti-mouse-, goat-, and rabbit-HRP were purchased from Pierce (Rockford, IL). Human recombinant TNF $\alpha$ was purchased from R\&D Systems. Small interfering (si)RNA against human Ang-2 was purchased from Invitrogen (Mount Waverley, Victoria, Australia).

\section{Cells and Cell Culture}

HUVECs were grown in M199 medium containing 20\% fetal calf serum (JRH, Brooklyn, Victoria, Australia) and endothelial growth factor supplement (BD BioSciences, North Ryde, NSW, Australia) as previously described. ${ }^{24}$ Cells were used at passage two or less.

\section{Flow Cytometry}

Expression of $\beta_{1}, \alpha_{5}, \alpha_{5} \beta_{1}$, VCAM-1, and E-selectin were determined on HUVECs with one-color flow cytometry using $1 \mu \mathrm{g}$ of antibodies described above added to the cells at $4^{\circ} \mathrm{C}$ for 30 minutes. The secondary antibody was anti-mouse Alexa 488 at 1:1000 dilution. The median fluorescence intensity was determined using a Beckman Coulter XL-MCL (Gladesville, NSW, Australia). 


\section{SK Activity Assay}

SK activity was determined as previously described. ${ }^{25}$ D-Erythro sphingosine (Biomol, Plymouth Meeting, PA) solubilized by $0.05 \%$ Triton $\mathrm{X}-100$ and $\left[\gamma^{32}\right.$ P]ATP (Perkin Elmer, Victoria, Australia) were used as substrates to incubate with the whole cell lysates. The radioactively labeled phospholipid was resolved by two thin-layer chromatography (Sigma, St. Louis, MO) separations in the solvents containing butanol, ethanol, water, and acetic acid (8:2:2:1 $\mathrm{ml})$. The radioactive spots were quantified by Phosphorimaging Typhoon 9410 (Fullerton, CA) and ImageQuant 5.2 program (GE Health care, Rydalmere, NSW, Australia).

\section{Inhibition Studies Using Human SK-1 Adenovirus Transduction}

Generation of wild-type human SK-1 wild-type (SK-1) and mutants possessing an aspartate at Glycine82 (SK-1-DN) have been made as previously described. ${ }^{26}$ For infection with adenoviral constructs, HUVECs were exposed to one plaque forming unit/cell for 2 hours in M119 medium with $2 \%$ fetal calf serum and a further 72 hours with medium containing 20\% fetal calf serum. Cells were infected with a dose of virus previously determined to lead to a five- to tenfold increase in SK-1 activity and the same dose of control EV adenovirus was used. ${ }^{17}$

\section{Immunofluorescence Microscopy}

Untreated or adenovirus infected EV, SK-1, and SK-1-DN HUVECs were replated at $5 \times 10^{4}$ cells/well in LabTek chamber slides (Nunc, NY) with fibronectin coated at 50 $\mu \mathrm{g} / \mathrm{ml}$. Confluent cells were fixed with $4 \%$ paraformaldehyde at room temperature for 15 minutes before blocking with $2 \%$ bovine serum albumin/PBS at room temperature for 30 minutes. Activated $\beta_{1}$ (QE.2E5), $\alpha_{5} \beta_{1}$ (BMC5), Ang-2, or control antibodies (1 $\mu \mathrm{g})$ were added to cells at $4^{\circ} \mathrm{C}$ overnight followed by anti-mouse Alexa 488 or antigoat Alexa 594 antibodies (1:1000) incubation at room temperature for 1 hour. The slides were mounted with anti-fading agents (Biomeda Corp, CA) before visualization by fluorescence microscopy (Olympus IX2-UCB, Olympus, Mt Waverley, Victoria, Australia). Five images, with four cells per image, were collected per sample and analyzed using Analysis LifeSciences software (Olympus).

\section{S1P Receptor Activation and Inhibition Studies}

S1P receptor activation and inhibition studies used S1P (1 $\mu \mathrm{mol} / \mathrm{L}$, Cayman Chemical Co., Ann Arbor, MI), JTE013 (1 $\mu \mathrm{mol} / \mathrm{L}$, Cayman Chemical Co.), and VPC23019 (10 $\mu \mathrm{mol} / \mathrm{L}$, Avanti Polar Lipids Inc., Alabaster, AL), which were administered either alone (for S1P) or 30 minutes before TNF $\alpha$ stimulation of cells ( $5 \mathrm{ng} / \mathrm{ml}, 5$ hours). All reagents were proven functionally effective in paralleled human umbilical vein EC studies. ${ }^{17}$

\section{Parallel Plate Flow Chamber Assay}

Confluent HUVECs were cultured on Corning petri dishes (Sigma) and treated with or without $5 \mathrm{ng} / \mathrm{ml} \mathrm{TNF} \alpha$ for 5 hours. Control, blocking antibodies $(10 \mu \mathrm{g} / \mathrm{ml})$, or SK inhibitor SKi (1 $\mu \mathrm{mol} / \mathrm{L}$, Cayman Chemical Co.) were added for 30 minutes before cell perfusion. Using published methods, heparinized whole blood was diluted 1:10 in Hank's balanced salt solution (Sigma) ${ }^{27}$ or used to isolate neutrophils ${ }^{28}$ and cells (diluted blood or $1 \times 10^{6}$ isolated neutrophils) were perfused across the substratum by a syringe pump (NE-1000, New Era Pump System, Inc, Wartagh, NY) at a constant rate of 2 dynes $/ \mathrm{cm}^{2}$ for 5 minutes followed by Hank's balanced salt solution wash. Interactions of unlabeled cells were visualized using $\times 10 / 0.3$ NA objectives and phase-contrast microscopy on an inverted microscope and images were recorded using a digital camera (Olympus IX70 and SIS F-view, Olympus). Five random areas per dish were recorded for analysis using AnalySIS Life Sciences software (Olympus). Adherent cells were defined as those remaining stationary for at least 10 seconds. Dishes were stained using the using May-Grunwald Giemsa (Sigma) according to the product protocol to identify leukocyte subsets.

\section{siRNA Transfection}

Adapted from methods previously described, ${ }^{29}$ Ang-2 siRNA (50 nmol/L) (HSS100480: 5'-AAUACUUCAGCACAGUCUCUGAAGC-3'; HSS100482:5'-UUCUCCUGAAGGGUUACCAAAUCCC-3') were transfected into HUVECs using HiPerfect (Qiagen, Doncaster, Victoria, Aust.) in EGMII medium (Clonetics/Lonza, Basel, Switzerland) when cells were at $60 \%$ confluency. After 24 hours, culture media were changed to the aforementioned tissue culture media until cells were harvested at 48 hours post-transfection.

\section{Immunoprecipitation and Immunoblotting}

HUVECs were harvested and lysed in lysis buffer containing 1\% NP40 and sonicated for immunoprecipitation. Following the manufacturers instructions, cell lysates were incubated with $\alpha_{5} \beta_{1}$ (MAB199) or Ang-2 (N-18) antibody and protein A magnetic beads (Miltenyi Biotech, Bergisch Gladbach, Germany) on ice for 30 minutes before selection by magnetic columns (Miltenyi Biotech). Whole lysates or immunoprecipitates were separated by $8 \%$ SDS-polyacrylamide gel electrophoresis and transferred to Hybond-P (Amersham Biosciences, NJ). Primary antibodies to phosphorylated ERK (197G2), total ERK (137F5), Ang-2 (N-18), or $\beta_{1}(58.7 \mathrm{H} 2)$ and secondary antibodies were used to probe the membranes before visualization by enhanced chemiluminescence (GE Health Science, Piscataway, NJ) and a luminescent image analyzer (LAS4000, Fujiflim; Stamford, CT).

\section{Statistical Analysis}

Data are shown as mean \pm SEM and statistically analyzed by Student's $t$-test, 1- or 2-way analysis of variance 
A

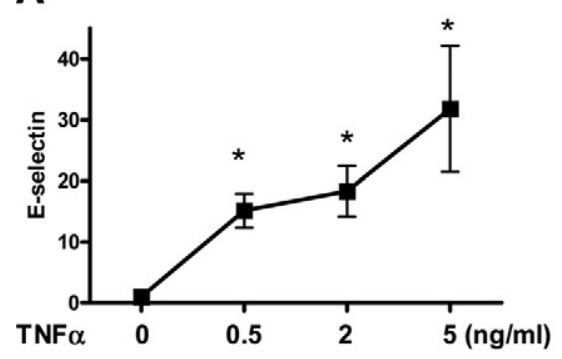

C

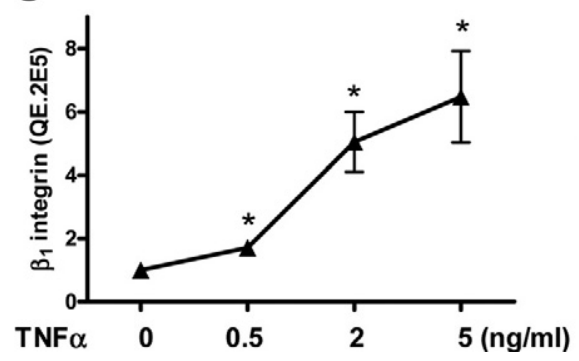

B

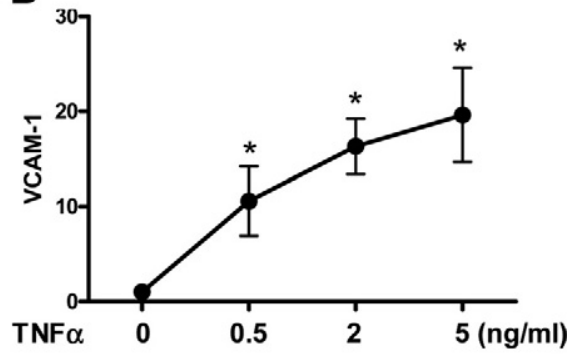

D

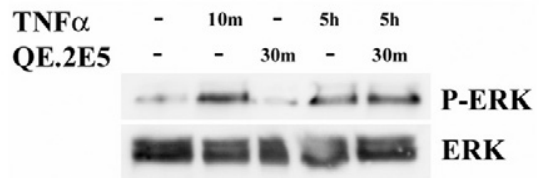

Figure 1. TNF $\alpha$ induced E-selectin, VCAM-1, and $\beta_{1}$ integrin expression on ECs. HUVECs were treated with TNF $\alpha(0,0.5,2$, or $5 \mathrm{ng} / \mathrm{ml}$, four hours) and examined for E-selectin (A), VCAM-1 (B), and activated $\beta_{1}$ integrin $(\mathbf{C})$ using the QE.2E5 $\mathrm{Ab}$ using flow cytometric analysis. Results are normalized to untreated control and expressed as the mean \pm SEM of seven experiments; ${ }^{*} P<0.05$ versus untreated controls (0). In $\mathbf{D}$, HUVECs treated without and with TNF $\alpha$ for ten minutes or five hours without or with QE.2E5 (30 minutes at $4^{\circ} \mathrm{C}$ ) before immunoblotting equal lysate amounts for P-ERK and total ERK. Results are representative of three experiments. for multiple comparisons. $P<0.05$ was considered as significant.

\section{Results \\ TNF $\alpha$ Activates $\beta_{1}$ Integrin on ECs}

With a similar profile to that observed for TNF $\alpha$-induced E-selectin and VCAM-1 expression, Figure 1, A-C shows a dose-dependent increase in $\beta_{1}$ integrin on HUVECs. As these flow cytometric data were obtained using the $\beta_{1}$ integrin QE.2E5 antibody, we propose that this increase in $\beta_{1}$ integrin may in fact represent an increase in $\beta_{1}$ activation. The concept of QE.2E5 binding to activated $\beta_{1}$, without causing activation, stems from it originally being developed against activated HUVECs ${ }^{22}$ and previous observations of it being without effect on the adhesive, proliferative, and tube-forming capabilities of both untreated and phorbol-12-myristate-13-acetate-treated HUVECs. ${ }^{23}$ To confirm that QE.2E5 does not activate HUVECs, we examined phosphorylation of ERK, an integrin-activated downstream signaling molecule. As shown in Figure 1D, addition of QE.2E5 to HUVEC for 30 minutes at $4^{\circ} \mathrm{C}$ did not phosphorylate ERK. By contrast, ERK is phosphorylated by TNF $\alpha$ at both 10 minutes and 5 hours (Figure 1D).

\section{TNF $\alpha$-Induced Activation of $\beta_{1}$ Integrin Is Sphingosine Kinase-1-Dependent}

To study the underlying mechanism of TNF $\alpha$-induced $\beta_{1}$ integrin activation we investigated a role for SK-1. First, $\mathrm{TNF} \alpha$-induced activation of SK-1 in ECs was confirmed using an enzymatic assay. As shown in Figure 2, TNF $\alpha$ activates SK-1 in a biphasic pattern with significant increases observed at 10 minutes and 4 to 6 hours after TNF $\alpha$ treatment. We next examined a role for SK-1 in $\beta_{1}$ integrin activation using an adenoviral delivery system to either overexpress SK-1 or knock down SK-1 catalytic activity with the dominant negative SK-1 mutant (SK-1DN). ${ }^{26,30}$ Data shown as supplemental Figure S1 (at $h t t p: / /$ ajp.amjpathol.org) demonstrate that both SK-1 and SK1-DN infected ECs exhibit a significant increase in SK-1 protein when compared with empty vector (EV) controls but that only SK-1 infected ECs express catalytically active SK-1 above control levels (see supplemental Figure S1, A and B, at http://ajp.amjpathol.org). Moreover, ECs overexpressing SK-1 exhibited a further increase in SK activity following TNF $\alpha$ stimulation for 4 hours. This was not observed in the SK-1-DN cells (see supplemental Figure S1B at http://ajp.amjpathol.org).

Flow cytometric analysis (using the QE.2E5 antibody) suggests that levels of activated $\beta_{1}$ integrin in untreated ECs do not differ between EV controls and SK-1 or SK1 -DN overexpressing cells (Figure 3B). Following TNF $\alpha$ activation, levels of active $\beta_{1}$ in EV-infected ECs increased approximately sevenfold. This increase was fur-

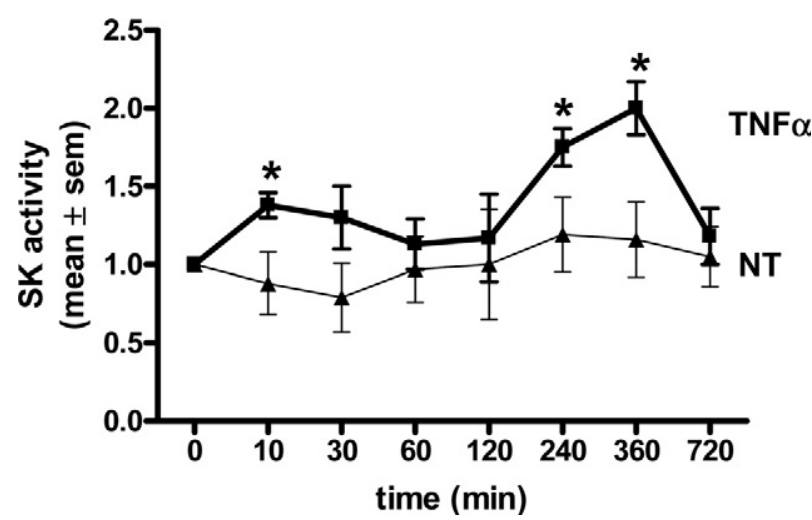

Figure 2. SK activity in ECs stimulated with TNF $\alpha$. Equal lysate amounts from HUVECs treated without (triangle, NT) and with TNF $\alpha$ (square) $(5 \mathrm{ng} / \mathrm{ml}: 10$, $30,60,120,240,360$, and 720 minutes) were assessed for SK activity by enzymatic assay. Results are the mean \pm SEM of $n=4$. ${ }^{*} P<0.05$ versus NT controls. 
A

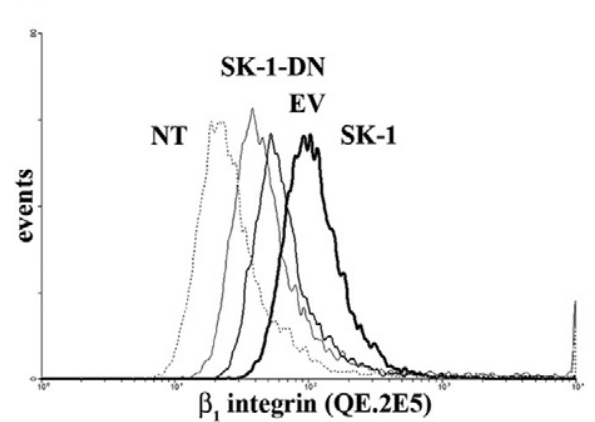

C

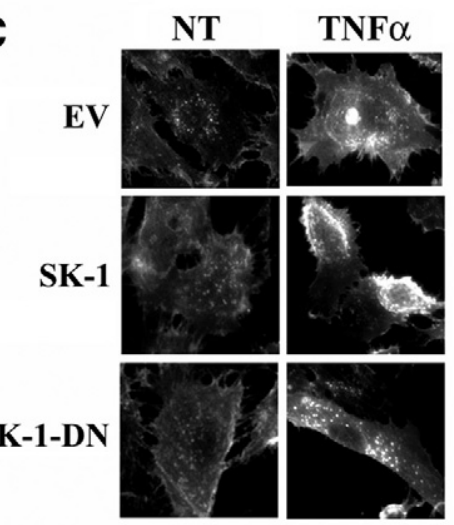

B

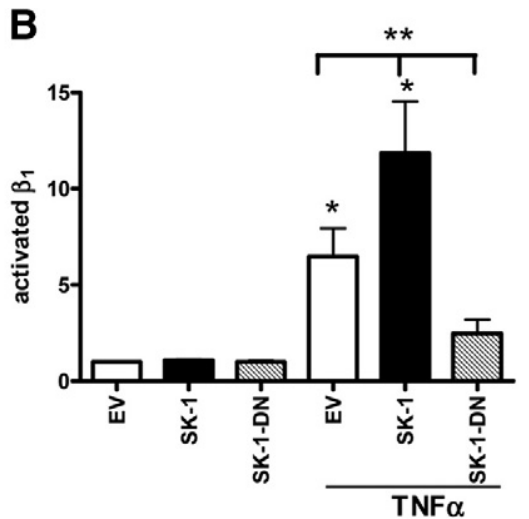

D

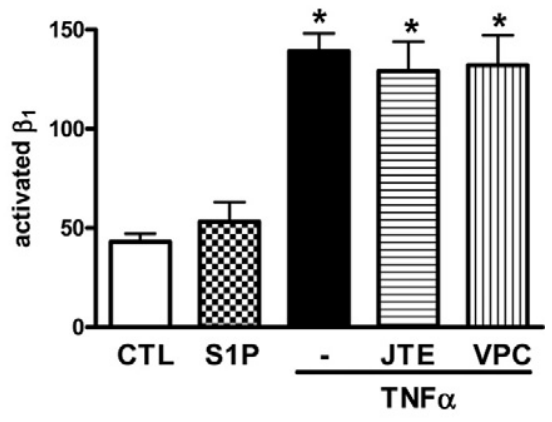

Figure 3. TNF $\alpha$ induces $\beta_{1}$ integrin activation in ECs overexpressing SK-1. HUVECs overexpressing SK-1, SK-1 dominant negative mutant (SK-1$\mathrm{DN})$, or EV control were stimulated without and with TNF $\alpha$ ( $5 \mathrm{ng} / \mathrm{ml}, 4$ hours $)$ and assessed for $\beta_{1}$ activation. In $\mathbf{A}$, trace files show a representative experiment with untreated (NT) controls and TNF $\alpha$ treated EV, SK-1, and SK-1-DN. In B, flow cytometric analysis of QE.2E5 stained pooled experiments as the mean \pm SEM, $n=7$. ${ }^{*} P<0.05$ versus untreated control; ${ }^{* *} P<0.05$ versus $\mathrm{TNF} \alpha$ treated $\mathrm{EV}$. In $\mathbf{C}$, immunofluorescence and confocal microscopy using the QE.2E5 Ab in NT and TNF $\alpha$ treated EV, SK-1, and SK-1-DN cells. In D, HUVECs were cultured without or with JTE-013 ( $1 \mu \mathrm{mol} / \mathrm{L})$ or VPC23019 $(10 \mu \mathrm{mol} / \mathrm{L}) 30$ minutes before S1P $(1 \mu \mathrm{mol} / \mathrm{L}, 4$ hours) or TNF $\alpha$ ( $5 \mathrm{ng} / \mathrm{ml}, 4$ hours $)$ stimulation. $\beta_{1}$ activation on ECs was assessed using immunofluorescence and mean fluorescence intensity quantified. Results are the mean \pm SEM of four cells/view, five views per sample, and three experiments. ${ }^{*} P<0.05$ versus untreated control. ther augmented in the ECs overexpressing SK-1 and not observed in the SK-1-DN ECs, which exhibited significantly less active $\beta_{1}$ integrin than both EV and SK-1 ECs (Figure 3, A and B). These results were supported by fluorescence microscopy, wherein increased active $\beta_{1}$ integrin was observed on the cell surface and edges of TNF $\alpha$-treated EV control cells. This effect was augmented in TNF $\alpha$-treated ECs overexpressing SK-1 and absent in the TNF $\alpha$-treated SK-1-DN cells (Figure 3C).

We next investigated whether the family of S1P receptors were involved in activation of $\beta_{1}$ integrin, using two methods. First, ECs cultured with $1 \mu \mathrm{mol} / \mathrm{L}$ S1P, a concentration known to result in receptor-mediated signaling events, ${ }^{20}$ exhibited no change in $\beta_{1}$ activation (Figure 3D). Second, chemical inhibition of the three S1P receptors identified on ECs (ie, $\mathrm{S}_{1} \mathrm{P}_{1}, \mathrm{~S}_{1} \mathrm{P}_{2}$, and $\mathrm{S}_{1} \mathrm{P}_{3}$ ) ${ }^{31}$ using JTE-013 and VPC23019 previously shown to inhibit S1Pinduced SK-1 activation in HUVECs ${ }^{17}$ failed to inhibit TNF $\alpha$-induced activation of $\beta_{1}$ integrin (Figure 3D).

Together, these results suggest that TNF $\alpha$ activates $\beta_{1}$ integrin at the cell surface, that SK-1 is integral to this process, and that this occurs independently of $\mathrm{S}_{1} \mathrm{P}_{1-3}$.

\section{Activation of $\beta_{1}$ Integrin by TNF $\alpha$ Does Not Correlate with Increased $\beta_{1}$ Integrin Protein}

We next investigated whether TNF $\alpha$-induced activation of $\beta_{1}$ integrin coincided with an increase in $\beta_{1}$ protein levels at the cell surface. Using flow cytometry and the $58.7 \mathrm{H} 2$ $\beta_{1}$ antibody, which does not specifically identify an activated conformation, we observed that the surface ex- pression levels of $\beta_{1}$ integrin in EV, SK-1, and SK-1-DN were similar without and with $\mathrm{TNF} \alpha$ treatment (Figure 4A). These observations were confirmed with a second antibody that recognizes a ligand binding site of $\beta_{1}$ integrin (61.2C4; Figure 4B). In addition to surface expressed $\beta_{1}$ integrin levels, we investigated total $\beta_{1}$ protein levels via immunoblotting. With a representative immunoblot shown in supplemental Figure S2 (at http://ajp.amjpathol.org) and pooled experimental results shown in Figure 4C; EV, SK-1, and SK-1-DN expressing ECs exhibit similar levels of $\beta_{1}$ integrin protein both without and with TNF $\alpha$ treatment. Together, these results suggest that neither TNF $\alpha$ treatment nor SK-1 overexpression altered total $\beta_{1}$ integrin protein levels either within or on the surface of ECs.

\section{TNF $\alpha$ Activates $\alpha_{5} \beta_{1}$ Co-Association in ECs}

To identify the $\alpha$ integrin subunit partnering $\beta_{1}$ following TNF $\alpha$ activation we performed immunoprecipitation assays using TNF $\alpha$-treated EC lysates and the activated $\beta_{1}$ integrin antibody QE.2E5. As shown in Figure 5A, immunoblots identified a close association between $\beta_{1}$ and $\alpha_{5}$ in untreated as well as TNF $\alpha$-treated ECs. Notably, from five experiments we observed an average of $18 \pm 5 \%$ increase in $\alpha_{5}$ association with $\beta_{1}$ integrin following TNF $\alpha$ stimulation. Despite previous studies reporting $\alpha_{2}$ subunit associating with $\beta_{1}$ in TNF $\alpha$-treated ECs, we were unable to detect this association following activated $\beta_{1}$ (QE.2E5) antibody pull-down (Figure 5A). Flow cytometric analysis confirmed a significant increase in surface expression 

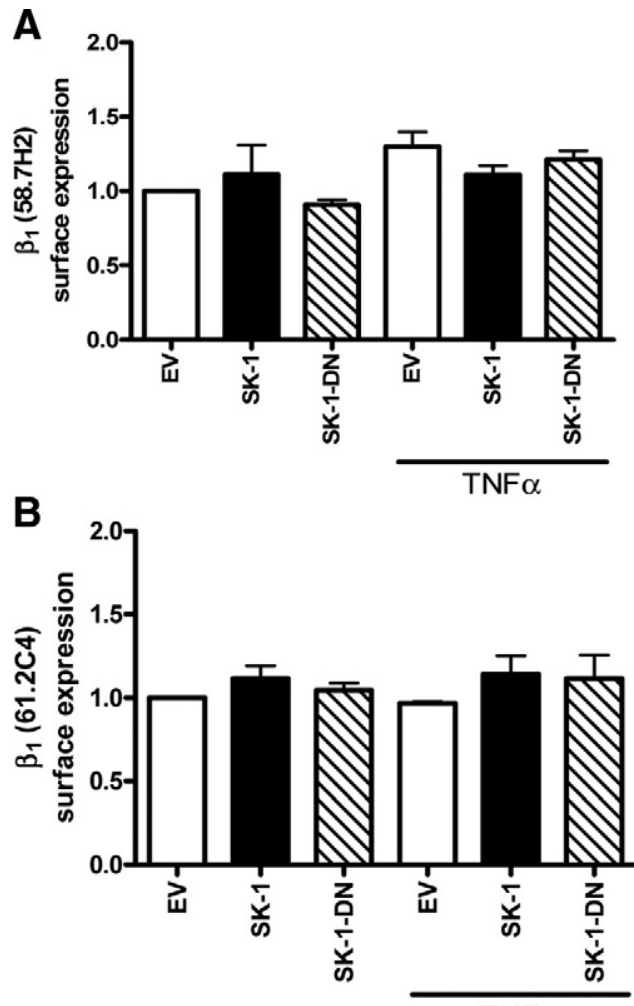

$\mathrm{TNF} \alpha$

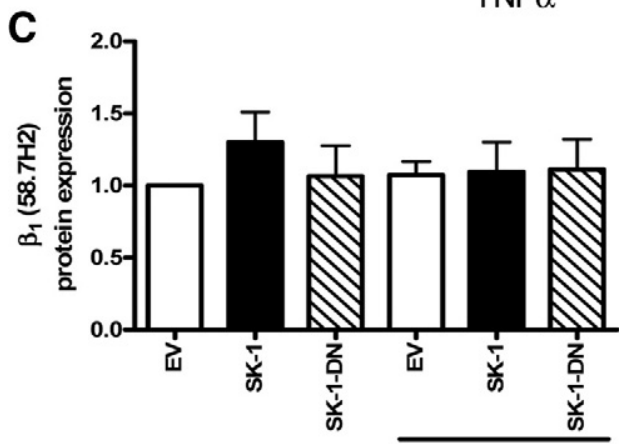

TNF $\alpha$

Figure 4. $\beta_{1}$ integrin surface expression and protein levels in ECs in response to TNF $\alpha$ treatment. HUVECs overexpressing SK-1, SK-1 dominant negative mutant (SK-1-DN), or EV control, were stimulated without and with TNF $\alpha$ ( $5 \mathrm{ng} / \mathrm{ml}$, four hours) and assessed for $\beta_{1}$ expression by flow cytometric analysis using $58.7 \mathrm{H} 2$ and $61.2 \mathrm{C} 4 \mathrm{Abs}(\mathbf{A}$ and $\mathbf{B}$ ) and immunoblotting using the $58.7 \mathrm{H} 2 \mathrm{Ab}(\mathbf{C})$. Results are expressed as the mean \pm SEM of three experiments (A and $\mathbf{B}$ ) or four experiments $(\mathbf{C})$

of $\alpha_{5}$, as well as $\alpha_{5} \beta_{1}$, on TNF $\alpha$-treated HUVEC (Figure 5, B-D).

\section{TNF $\alpha$-Induced Activation of $\alpha_{5} \beta_{1}$ on HUVECs Mediates Leukocyte Adhesion}

To investigate the function of TNF $\alpha$-induced activation of $\beta_{1}$ integrin on ECs, we examined its role in leukocyte adhesion by a parallel plate flow chamber assay. As shown in Figure 6A (and supplemental Video S1, at http:// ajp.amjpathol.org), when human blood was perfused over untreated HUVECs at a rate of 2 dynes $/ \mathrm{cm}^{2}$, negligible leukocyte adhesion was observed. By contrast, when stimulated with $\mathrm{TNF} \alpha$, a significant increase in leukocyte
A

NT TNF $\alpha$ lysate

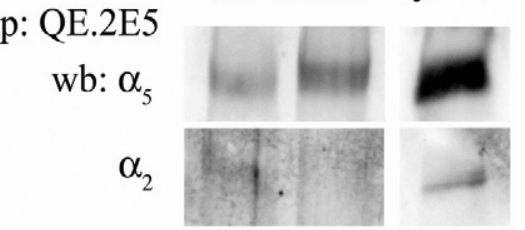

B

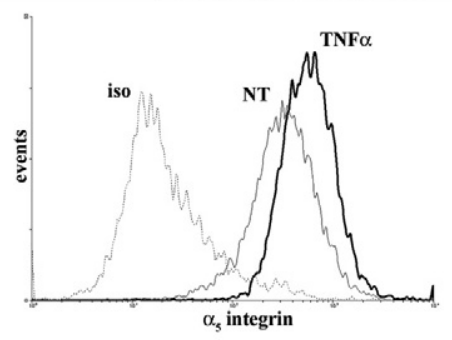

C
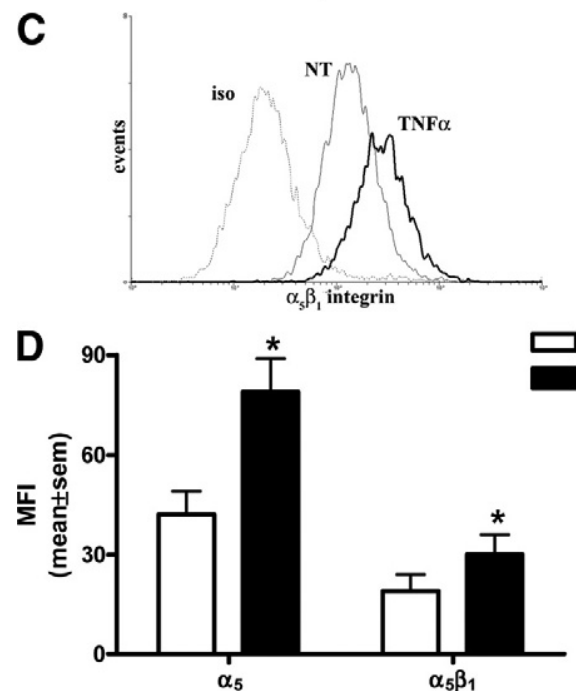

Figure 5. TNF $\alpha$ activated $\beta_{1}$ integrin is co-associated with $\alpha_{5}$. HUVECs were treated without and with TNF $\alpha(5 \mathrm{ng} / \mathrm{ml}$, four hours) before immunoprecipitation of equal lysate amounts with QE.2E5 to pull down activated $\beta_{1}$ integrin (A). Precipitates were examined for $\beta_{1}$ co-association with $\alpha_{5}$ and $\alpha_{2}$ integrin via immunoblotting. Gel lanes from the same experiment have been cut and re-orientated to better illustrate the whole HUVEC lysate positive controls (lysate). Results are representative of five experiments. In $\mathbf{B}$ and $\mathbf{C}$, HUVECs were treated without (NT) and with TNF $\alpha(5 \mathrm{ng} / \mathrm{ml}$, four hours) before flow cytometric analyses for $\alpha_{5}$ and $\alpha_{5} \beta_{1}$ integrin surface expression, respectively, and are a representative of three experiments relative to isotype control (iso). In $\mathbf{D}$, similar experiments were quantified for mean fluorescence intensity (MFI) of $\alpha_{5}$ and $\alpha_{5} \beta_{1}$ surface expression. Results are mean \pm SEM, $n=3$; ${ }^{*} P<0.05$ versus NT.

adhesion occurred. When TNF $\alpha$ stimulated ECs were exposed to a $\beta_{1}$ blocking antibody (61.2C4) 30 minutes before flow chamber assay, the number of adherent cells was significantly reduced. A similar profile of reduced leukocyte adhesion was also observed with an $\alpha_{5}$ blocking antibody. No change was observed with either an isotype control or a blocking antibody to $\alpha_{2}$ (confirmed to inhibit ECs attachment to collagen) (Figure 6A). A role for $\mathrm{SK}$ in TNF $\alpha$-induced leukocyte adhesion was confirmed in experiments wherein an SK inhibitor, SKi, was added 30 minutes before flow chamber assay (Figure 6A). These results suggest that TNF $\alpha$-induced leukocyte adhesion to ECs is, at least in part, mediated by the integrin $\alpha_{5} \beta_{1}$ and the SK/S1P pathway. The role for $\alpha_{5}$ and $\beta_{1}$ combined in leukocyte adhesion was next examined us- 

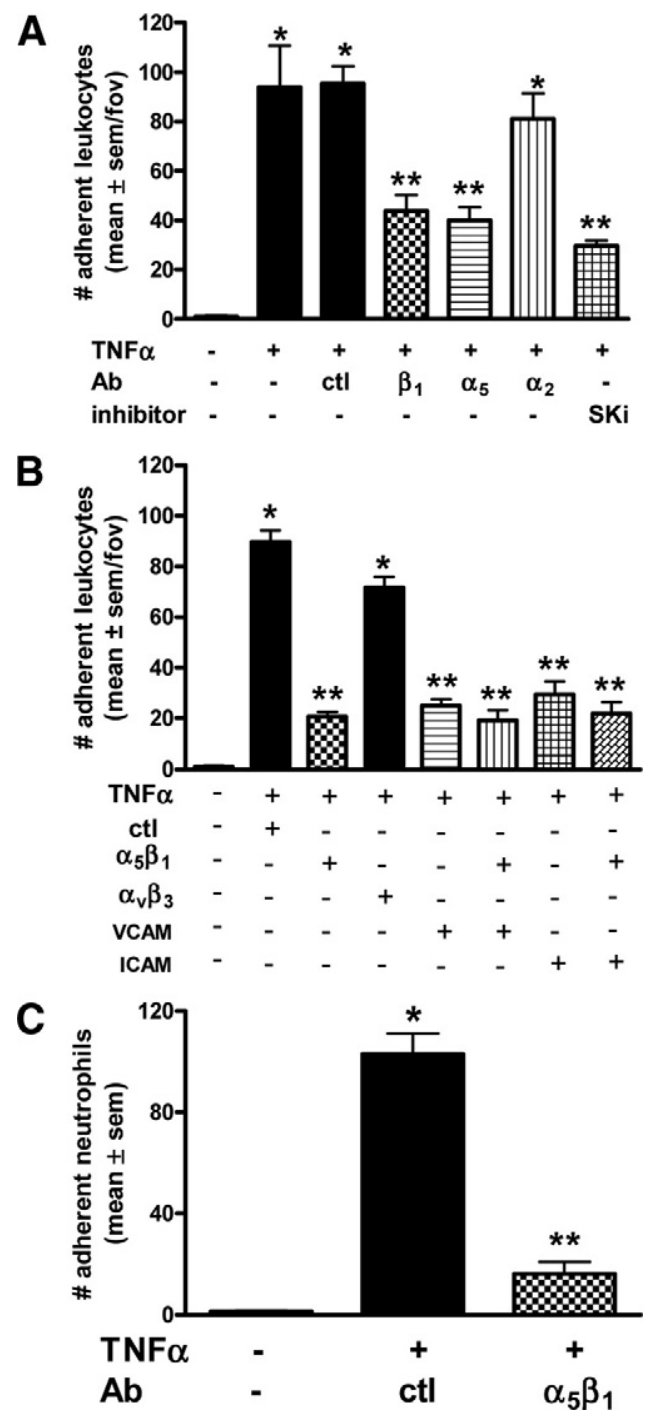

Figure 6. Leukocyte adhesion to TNF $\alpha$-activated ECs under shear flow Adhesion of leukocytes on HUVECs stimulated without and with TNF $\alpha$ (5 $\mathrm{ng} / \mathrm{ml}$, four to five hours) using the parallel plate flow chamber assay at a constant shear rate of 2 dynes $/ \mathrm{cm}^{2}$ and pre-incubation of ECs in $\mathbf{A}$ with control (ctl) or blocking Abs to $\beta_{1}, \alpha_{5}, \alpha_{2}$, or the SK inhibitor (SKi, $1 \mu \mathrm{mol} / \mathrm{L}$ ), for 30 minutes prior. In $\mathbf{B}$, blocking Abs to $\alpha_{5} \beta_{1}, \alpha_{v} \beta_{3}$, VCAM, and ICAM for 30 minutes prior. In $\mathbf{C}$, isolated neutrophils are perfused $\left(1 \times 10^{6} / \mathrm{ml}\right)$ as above and pre-incubation of ECs with control (ctl) or blocking Abs to $\alpha_{5} \beta_{1}$ for 30 minutes prior. Data are expressed as the mean \pm SEM per field of view (fov) with four to five fov captured for three to four separate experiments. ${ }^{*} P<0.05$ relative to untreated $(-)$ controls; ${ }^{* *} P<0.05$ relative to TNF $\alpha$ stimulated adhesion.

ing the $\alpha_{5} \beta_{1}$ blocking antibody (BMC5). As shown in Figure $6 \mathrm{~B}$, administration of the $\alpha_{5} \beta_{1}$ antibody significantly reduced leukocyte adhesion to TNF $\alpha$-treated HUVECs. This inhibition was not observed with the $\alpha_{\mathrm{v}} \beta_{3}$ blocking antibody (LM609) (Figure 6B), an integrin also activated by SK-1. ${ }^{19}$ As TNF $\alpha$ is also known to regulate VCAM-1 and ICAM-1 expression on HUVECs via SK-1, ${ }^{20}$ we next investigated their contribution to $\alpha_{5} \beta_{1}$-mediated leukocyte adhesion. As shown in Figure 6B, antibodies to $\alpha_{5} \beta_{1}$, VCAM- 1 and ICAM-1, alone, or together, demonstrated a similar level of inhibition.

May-Grunwald Giemsa staining of the dishes at completion of the aforementioned experiments identified neu- trophils as the leukocyte subset targeted by $\alpha_{5} \beta_{1}$ for adhesion (data not shown). This was confirmed with isolated neutrophils in flow chamber assays. As shown in Figure 6C, when TNF $\alpha$-stimulated ECs were exposed to the $\alpha_{5} \beta_{1}$ blocking antibody (BMC5) 30 minutes before flow chamber assay, the majority of neutrophils could no longer adhere.

\section{Angiopoietin-2 Associates with $\alpha_{5} \beta_{1}$ to Mediate TNF $\alpha$-Induced Leukocyte Adhesion}

Previous studies have shown that Ang-2 production by ECs is significantly increased following TNF $\alpha$ stimulation. ${ }^{32}$ More importantly for this study, Ang-2 is a known ligand for $\alpha_{5} \beta_{1}$ on ECs. ${ }^{33}$ Increased Ang-2 expression by ECs following TNF $\alpha$ activation was first confirmed by fluorescence microscopy on HUVECs overexpressing SK-1, SK-1-DN, or EV control. As shown in supplemental Figure S3A (at http://ajp.amjpathol.org), untreated ECs exhibit an Ang-2 expression that is low and diffuse over the cell surface. This expression increases in a similar pattern following TNF $\alpha$ activation. Figure 7A shows quantitation of the immunofluorescence data and suggests that TNF $\alpha$ promotes Ang-2 surface presentation by approximately fourfold. When ECs overexpress SK-1, TNF $\alpha$-mediated Ang-2 expression is further increased. This effect is not observed in the SK-1-DN ECs where TNF $\alpha$-induced Ang-2 expression is significantly abrogated (Figure 7A).

As Ang-2 is a known ligand for $\alpha_{5} \beta_{1}$ on $\mathrm{ECs}^{33}$ we next investigated their endogenous association in ECs without and with TNF $\alpha$ activation. Immunoprecipitations targeting Ang-2 identified its close association with $\beta_{1}$ integrin (Figure 7B) with repeated experiments suggesting an increase of approximately $10 \%$ following TNF $\alpha$ activation. Reciprocal immunoprecipitations targeting $\alpha_{5} \beta_{1}$ and immunoblotting against Ang-2 confirmed an increase in $\alpha_{5} \beta_{1}$ :Ang-2 complex formation in ECs following TNF $\alpha$ activation. From repeated experiments, an average of $21 \pm 12 \%$ increase in Ang-2 association with $\alpha_{5} \beta_{1}$ integrin occurred following TNF $\alpha$ activation.

We next investigated whether Ang-2 is involved in leukocyte adhesion under flow using Ang-2 specific siRNAs. Immunoblots first confirmed a significant reduction in Ang-2 protein levels when compared with ECs transfected with a negative control siRNA (see supplemental Figure S3B at http://ajp.amjpathol.org). Importantly, when ECs are depleted of Ang-2 by siRNA the number of adherent leukocytes under flow is significantly reduced when compared with the control siRNA-transfected ECs (Figure 7C and supplemental Video S2 at http://ajp. amjpathol.org). These results were confirmed using a second Ang-2 siRNA and Giemsa May-Grunwald staining of the dishes supported previous data of neutrophils being targeted by this process. Finally, Figure 7D shows immunofluorescence staining following flow chamber assay for $\alpha_{5} \beta_{1}$ (green) and Ang-2 (red), which indicate similar expression patterning on TNF $\alpha$-treated HUVECs. The close 
A

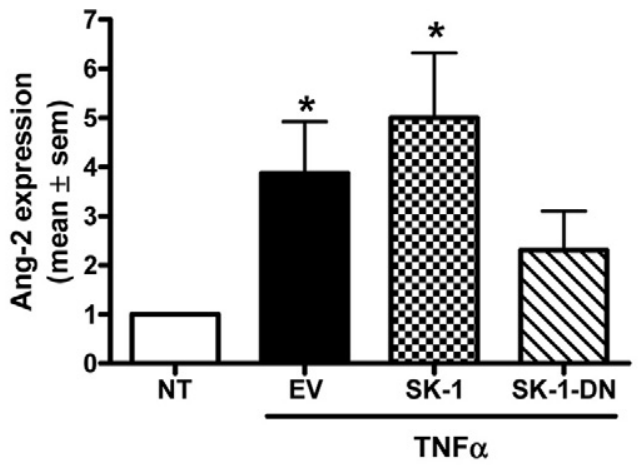

B TNF $\alpha$
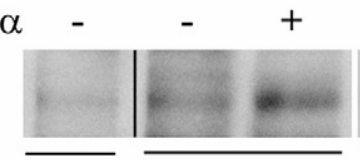

ip: ctl Ang-2
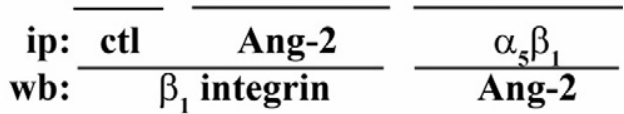

C
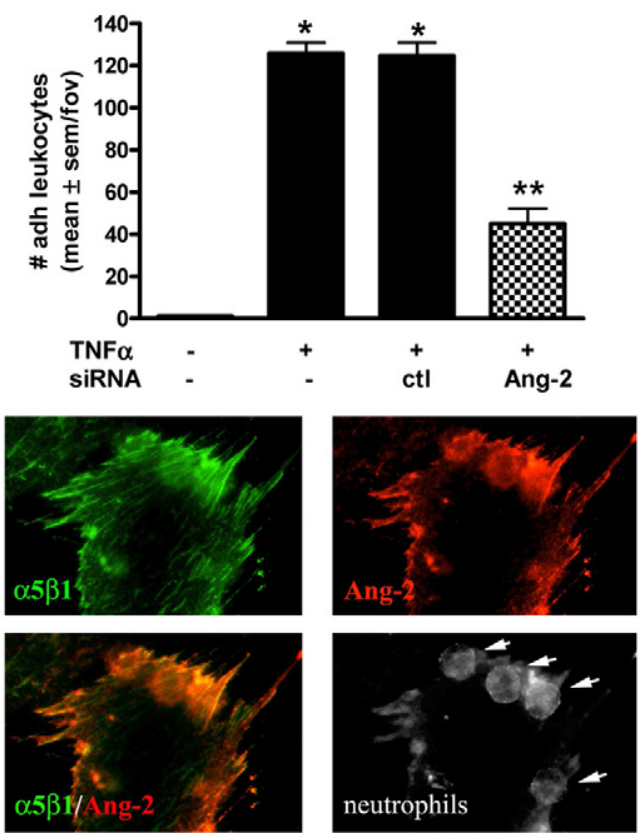

Figure 7. Ang-2 expression in TNF $\alpha$-treated ECs and leukocyte adhesion under shear flow. In A, HUVECs overexpressing SK-1, SK-1 dominant negative mutant (SK-1-DN), or EV control were stimulated without (NT) and with TNF $\alpha(5 \mathrm{ng} / \mathrm{ml}$, four hours) and quantified for Ang-2 surface expression by immunofluorescence. Results are the normalized mean \pm SEM of approximately 100 cells from a total of five experiments; ${ }^{*} P<0.05$ versus untreated controls (NT). In $\mathbf{B}$, equal lysate amounts from HUVECs treated without and with TNF $\alpha(5 \mathrm{ng} / \mathrm{ml}$, four hours) were immunoprecipitated for Ang-2 or $\alpha_{5} \beta_{1}$. Precipitates were examined for $\alpha_{5} \beta_{1}$ and Ang-2 co-association via immunoblotting. Gel lanes from the same experiment have been cut and re-orientated to better illustrate the changes from isotype control $\mathrm{Ab}(\mathrm{ctl})$ ip. Results are representative of five experiments. In $\mathbf{C}$, HUVECs containing siRNA to Ang-2 or ctl were stimulated without and with TNF $\alpha(5 \mathrm{ng} / \mathrm{ml}$, four to five hours) and assessed for leukocyte adhesion by flow chamber assay at a constant shear rate of $2 \mathrm{dynes} / \mathrm{cm}^{2}$. Data are expressed as the mean \pm SEM per field of view (fov) with four to five fov captured for five separate experiments. ${ }^{*} P<0.05$ relative to untreated $(-)$ controls; ${ }^{* *} P<0.05$ relative to TNF $\alpha$ stimulated ctl siRNA cells. In $\mathbf{D}, \alpha_{5} \beta_{1}$ (green) and Ang-2 (red) surface expression, as well as neutrophil localization (arrows) were viewed by immunofluorescence in HUVECs treated with TNF $\alpha(5 \mathrm{ng} / \mathrm{ml}$, four hours) by confocal microscopy.

association of these two proteins is further supported by the merged image in Figure 7D $\left(\alpha_{5} \beta_{1} /\right.$ Ang-2) where $\alpha_{5} \beta_{1}$ and Ang-2 clearly overlay. Furthermore, a change in focal plane of this image identified the localization of neutro- phils in close proximity to $\alpha_{5} \beta_{1}$ and Ang-2 at the cell junction (Figure 7D, neutrophils, arrows). Together these results support our hypothesis that $\mathrm{TNF} \alpha$-induced neutrophil adhesion to ECs under flow is mediated by a complex of active $\alpha_{5} \beta_{1}$ and Ang-2.

\section{Discussion}

Inappropriate activation or recruitment of leukocytes has been implicated in the pathogenesis of various inflammatory diseases (reviewed in 2). Herein we demonstrate that TNF $\alpha$ induces $\alpha_{5} \beta_{1}$ activation via an SK-1-dependent pathway in HUVECs. We show that SK-1 overexpression in ECs, to levels of activity equivalent to that seen after vascular endothelial growth factor or other growth factor stimulation, sensitizes the cells to TNF $\alpha$ and has a crucial role in $\alpha_{5} \beta_{1}$ integrin activation and neutrophil adhesion under shear flow. Evidence for this comes from firstly, the binding of the QE.2E5 antibody, previously shown to bind to activated $\beta_{1}$ integrin via a conformation sensitive epitope $^{22}$ when SK-1 is overexpressed. Notably, this TNF $\alpha$-induced activation of $\beta_{1}$ does not coincide with increased protein levels but does correlate with increased expression of $\alpha_{5}$ as well as formation of $\alpha_{5} \beta_{1}$, as demonstrated by immunoblotting and flow cytometric analysis of TNF $\alpha$-treated ECs. TNF $\alpha$-induced $\alpha_{5} \beta_{1}$ activation in ECs promotes neutrophil adhesion under physiologically relevant shear flow and this occurs in an SK1-dependent, S1P $\mathrm{P}_{1-3}$-independent, manner. Finally, in response to TNF $\alpha$ activation, ECs exhibit an SK-1-dependent, increased surface expression of Ang-2, which is biologically important for neutrophil adhesion.

Herein, we propose that TNF $\alpha$ treated HUVEC exhibit increased activation of $\beta_{1}$ integrin. This concept is primarily derived from increased binding of the QE.2E5 monoclonal antibody, which was originally developed against lipopolysaccharide-activated HUVEC. ${ }^{22}$ QE.2E5 is unique in that it binds to $\beta_{1}$ integrin at amino acid residues 426-587, a site 194 amino acids distal from the binding site of ligands and other function-modifying $\beta_{1}$ antibodies. $^{22}$ Our data support the notion that QE.2E5 identifies activated $\beta_{1}$ integrin on HUVECs with 1) TNF $\alpha$ activated HUVECs expressing more $\alpha_{5} \beta_{1}$ complex at their cell surface, 2) no change in $\beta_{1}$ surface expression or protein using antibodies $58.7 \mathrm{H} 2$ and $61.2 \mathrm{C} 4$, and 3) increased binding of Ang-2 to $\alpha_{5} \beta_{1}$ on TNF $\alpha$-treated HUVEC. With the assumption that $\beta_{1}$ integrin does not exist without an $\alpha$ partner at the cell surface, this implies that the TNF $\alpha$-induced $\alpha_{5} \beta_{1}$ formation is a result of $\beta_{1}$ switching from another integrin heterodimer. The integrin from which this $\beta_{1}$ subunit is derived is yet to be determined with $\alpha_{2} \beta_{1}$ a likely candidate (Figure 5A). Interestingly, despite QE.2E5 previously shown to activate $\beta_{1}$ integrin function on the erythroleukemic cell line $\mathrm{K} 562^{22}$ and thymocytes ${ }^{34}$ it remains without effect on the adhesive, proliferative, and tube-forming capabilities of both untreated and phorbol-12-myristate-13-acetate-treated HUVECs, ${ }^{23}$ as well as ERK activation on TNF $\alpha$-treated HUVECs (Figure 1). The physiological significance of such alternative conformational effects by QE.2E5 on 
different cell types is uncertain. It is tempting to speculate that the lipopolysaccharide-activated HUVECs, first used to develop QE.2E5, underwent an inside-out signaling event, which altered the conformation of $\beta_{1}$ integrin at residues $426-587$, and as such, identifies agonist induced $\beta_{1}$ activate conformation specific to HUVECs.

Despite our significant progress in the knowledge of the neutrophil adhesion cascade, there are still several caveats in our understanding. In particular, the relative importance of each adhesion receptors in response to specific stimuli for tissue- and vascular bed-specific inflammatory cell recruitment needs to be established. Some light may have been shed on this issue by previous studies, which demonstrated a role for $\alpha_{5} \beta_{1}$ in the migration of neutrophils, ${ }^{35-37}$ as well as the adhesion of monocytes. ${ }^{38}$ These studies clearly suggest that leukocyte interactions with the endothelium may rely on the assembly of complexes, which contain different adhesion molecules. Our observations that inhibiting $\beta_{1}$ abrogated, in part, neutrophil adhesion to TNF $\alpha$-treated HUVEC under shear flow is in keeping with other studies demonstrating the contribution of TNF $\alpha$-induced expression of VCAM- 1 and ICAM-1 to leukocyte adhesion (reviewed in 39). Furthermore, when $\alpha_{5} \beta_{1}$ is blocked in addition to VCAM-1 and ICAM-1 a slight, but insignificant reduction in neutrophil adhesion was observed. The full relationship between $\alpha_{5} \beta_{1}$ and other TNF $\alpha$-induced adhesion molecules is still to be fully elucidated, but our work suggests that an interrelationship between these molecules may exist. Given the wide distribution of integrins throughout the body, the need for stringent regulation of their interactions might be well anticipated. Indeed, studies to date suggest that a certain threshold level of integrin expression, as well as conversion to the active form, is required to engage ligands-a conversion that is cell type- and stimuli-specific. Such selectivity is exemplified by opioids that trigger $\alpha_{5} \beta_{1}$ integrin-mediated monocyte adhesion ${ }^{38}$ and f-Met-Leu-Phe, but not leukotriene B4 activation of $\alpha_{5} \beta_{1}$ for neutrophil adhesion to fibronectin. ${ }^{40}$ In further support, studies suggest that the activated form of $\alpha_{5} \beta_{1}$ is a transient property of activated ECs, and can therefore be used only within a confined time frame (reviewed in 3). Our data now extend this work by suggesting that TNF $\alpha$ activates the endothelium for $\alpha_{5} \beta_{1}$-dependent neutrophil adhesion under shear flow.

Ang-1 and Ang-2 are structurally related endothelial growth factors found on the extracellular surface of ECs with Tie-2 considered to be their principle cell surface receptor. ${ }^{41}$ While Ang-1 mediates vessel maturation and maintains vessel integrity, Ang-2, in contrast, is classically considered as a functional antagonist of Ang-1 and binds to Tie-2 without inducing signal transduction. ${ }^{42}$ Mice transgenically overexpressing Ang-2 have an embryonic lethal phenotype that essentially phenocopies Ang-1-deficient and Tie-2-deficient phenotypes. ${ }^{41-43} \mathrm{In}$ terestingly, genetic ablation of Ang-2 is also lethal with postnatal mortality of newborn pups occurring by day 14 . However, this lethality is entirely dependent on the genetic background of the mice with the 129/J and C57BL/6 strains being more and less susceptible, respectively. ${ }^{44,45}$ Ang-2 acts by an autocrine mechanism and is stored in
Weibel-Palade bodies from where it can be rapidly released on stimulation. ${ }^{46} \mathrm{~A}$ role for Ang-2 in leukocyte recruitment is evidenced by Fiedler and colleagues who recently showed that Angpt-2-/- mice could not elicit an inflammatory response in thioglycollate-induced or Staphylococcus aureusinduced peritonitis, or in the dorsal skin fold chamber model. ${ }^{45}$ Furthermore, intravital microscopy showed normal TNF $\alpha$ induced leukocyte rolling but not adhesion in the vasculature of Angpt-2-/- mice. Cellular experiments also suggest that Ang-2 promotes cell adhesion by modulating TNF $\alpha$ induced expression of the EC adhesion molecules ICAM and VCAM. ${ }^{45}$ Finally, a close association between the angiopoietins and $\alpha_{5} \beta_{1}$ has previously been demonstrated in pull-down assays and is suggested to be Tie-2 independent. ${ }^{47,48}$ Our study supports these observations with TNF $\alpha$-induced neutrophil recruitment being both $\alpha_{5} \beta_{1}$ - and Ang-2-dependent and that a relationship with VCAM-1 and ICAM-1, but not $\alpha_{v} \beta_{3}$, may exist.

SK-1 can exist in a basal, intrinsic state that we have shown inhibits EC permeability. ${ }^{29}$ SK-1 also has an agonist-induced activated state, which occurs, at least in response to TNF $\alpha$ and phorbol ester, as a direct consequence of phosphorylation at serine 225 by ERK $1 / 2{ }^{30}$ The effects of this single phosphorylation are two-fold: it is required for agonist induced increases in the catalytic activity of SK-1, and it is necessary for translocation of this protein from the cytosol to the plasma membrane. ${ }^{18}$ We have recently demonstrated a requirement of SK-1 phosphorylation at serine 225 for increased heterotrimeric complex formation between SK-1, $\alpha_{\mathrm{v}} \beta_{3}$ and CD31 following factor deprivation where $\alpha_{\mathrm{v}} \beta_{3}$ activation and subsequent EC survival signals include the $\mathrm{BCl}-\mathrm{X}$ and nuclear factor $\kappa \mathrm{B}$ pathways. ${ }^{19}$ Herein we demonstrate, for the first time, that SK-1 is integral for TNF $\alpha$-induced $\alpha_{5} \beta_{1}$ activation, Ang-2 expression and neutrophil adhesion under shear flow. Whether phosphorylation of SK-1 is also involved in this process is still to be determined. Furthermore, we suggest that TNF $\alpha$-induced activation of $\alpha_{5} \beta_{1}$ is S1P receptor independent as inhibition of S1P $\mathrm{P}_{1-3}$ function, as well as S1P administration (at a concentration specific for receptor engagement ${ }^{49}$ ) did not alter QE.2E5 antibody binding capabilities. The possibility that TNF $\alpha$ induced adhesion molecule expression requires SK-1/ S1P to act intracellularly supports the initial observations by Xia and co-workers. ${ }^{50}$ Briefly, Xia et al ${ }^{50}$ demonstrated that the effective concentrations of S1P to mediate adhesion molecule expression were in the micromolar range despite the $K_{d}$ for $S 1 P_{1-3}$ on ECs being 20 to $60 \mathrm{nmol} / \mathrm{L}$. Furthermore, neither pertussis toxin (a $\mathrm{G} \alpha_{\mathrm{i}}$ inhibitor) nor suramin (a nonspecific phospholipid receptor inhibitor) could effectively block S1P induction of adhesion molecules. ${ }^{20}$ These observations are however in contrast to the suppressive effect of S1P on $\alpha_{5} \beta_{1}$-mediated monocyte adhesion to ECs. ${ }^{51}$ Aoki and colleagues ${ }^{51}$ recently demonstrated that S1P-induced activation of HUVECs inhibited U937 adhesion by shifting the localization of $\alpha_{5} \beta_{1}$ from the apical surface to the basal surface. This S1P-induced suppressive effect was $\mathrm{S}_{1} \mathrm{P}_{1}$ and $\mathrm{S}_{1} \mathrm{P}_{3}$ receptor-mediated, as demonstrated by inhibition studies, as well as specific inhibitors of $\mathrm{G} \alpha_{\mathrm{i}}$ protein, Src family proteins, phosphatidylinositol 3-kinase, and Rac1. ${ }^{51}$ The 
differences observed between this and our own observations may be explained by the use of a myeloid cell line and a static adhesion assay by Aoki et al ${ }^{51}$ versus ours of whole blood or neutrophils and adhesion under conditions of physiologically relevant shear flow. The very recent identification of histone deacetylases as intracellular targets of S1P by Hait and colleagues ${ }^{16}$ suggests a new paradigm of S1P signaling within the nucleus. Whether transcriptional regulation of EC adhesion molecules occurs via this mechanism is interesting to speculate and requires further investigation. Another aspect that requires further elucidation with respect to TNF $\alpha$-induced, SK-1-dependent adhesion molecule expression is the timing of SK activity. We show here a biphasic response of SK activity in ECs following TNF $\alpha$ activation: the first occurring within 10 minutes and the second approximately 4 to 6 hours later. Whether $\mathrm{TNF} \alpha$-induced $\mathrm{E}$-selectin, VCAM-1, ICAM- 1 , and now, $\alpha_{5} \beta_{1}$, expression are reliant on the first and/or second wave of SK activity is currently under investigation within our laboratory.

Neutrophils are the most abundant blood-borne leukocytes in healthy humans and they accumulate within hours at sites of acute inflammation. Moreover, they are essential for combating bacterial and fungal infections, but their activation also releases cytotoxic mediators, causing tissue damage. These studies support that the paradigm of neutrophil trafficking as a multistep cascade determined by a variety of adhesion receptors continues to serve as a useful model, but needs to be refined to accommodate Ang-2 and other non-selectin and cellular adhesion molecules. The findings presented here add new complexities that broaden the accepted concept of neutrophil trafficking, as we show that primary adhesive events of neutrophils, in vitro, are dependent on $\alpha_{5} \beta_{1}$ and Ang-2. The precise mechanisms underpinning $\alpha_{5} \beta_{1}$ :Ang2-mediated neutrophil adhesion require further investigation. We propose a sandwich type configuration between $\alpha_{5} \beta_{1}$ and Ang-2, where Ang-2 acts as a bridge to mediate $\alpha_{5} \beta_{1}: \alpha_{5} \beta_{1}$-dependent cellular events between neutrophils and TNF $\alpha$-activated HUVECs. A similar system was recently observed with Th1 and Th2 lymphocytes, wherein hyaluronan mediates the CD44:CD44 dependent rolling and adhesion to the intestine of TNF $\alpha$-treated mice. ${ }^{27}$ Our observations now suggest that SK-1/S1P is integral to controlling all three families of adhesion molecules, namely, selectins, cellular adhesion molecules, and integrins. Taken together these results suggest that SK-1 may be the single target required for an effective broad spectrum therapeutic target to combat inflammatory and immune disorders.

\section{Acknowledgments}

We thank Anna Sapa, Samantha Escarbe, and Michaelia Cockshell for preparing the endothelial cells; Prof. Jennifer Gamble, Milena Stankovic, and Dr. Jeffrey Barrett for production of the adenovirus; Prof. Jennifer Gamble for antibodies; and the staff and consenting donors at Women's and Children's Hospital and Burnside Memorial Hospital for collection of the umbilical cords.

\section{References}

1. Luster $A D$, Alon $R$, von Andrian UH: Immune cell migration in inflammation: present and future therapeutic targets. Nat. Immunol. 2005; 6:1182-1190

2. Hickey MJ, Kubes P: Intravascular immunity: the host-pathogen encounter in blood vessels. Nat Rev Immunol 2009; 9:364-375

3. Abram CL, Lowell CA: The ins and outs of leukocyte integrin signaling. Annu Rev Immunol 2009, 27:339-362

4. Alon R, Ley K: Cells on the run: shear-regulated integrin activation in leukocyte rolling and arrest on endothelial cells. Curr Opin Cell Biol 2008, 20:525-532

5. Chan JR, Hyduk SJ, Cybulsky MI: Chemoattractants induce a rapid and transient upregulation of monocyte alpha4 integrin affinity for vascular cell adhesion molecule 1 which mediates arrest: an early step in the process of emigration. J Exp Med 2001, 193:1149-1158

6. Steinman L: Blocking adhesion molecules as therapy for multiple sclerosis: natalizumab. Nat Rev Drug Discov 2005, 4:510-518

7. Lebwohl M, Tyring SK, Hamilton TK, Toth D, Glazer S, Tawfik NH, Walicke P, Dummer W, Wang X, Garovoy MR, Pariser D: A novel targeted T-cell modulator, efalizumab, for plaque psoriasis. N Engl J Med 2003, 349:2004-2013

8. Yonekawa K, Harlan JM: Targeting leukocyte integrins in human diseases. J Leukoc Biol 2005, 77:129-140

9. Croft M: The role of TNF superfamily members in T-cell function and diseases. Nat Rev Immunol 2009, 9:271-285

10. Alemany R, van Koppen CJ, Danneberg K, Ter BM, Meyer Zu HD: Regulation and functional roles of sphingosine kinases. Naunyn Schmiedebergs Arch Pharmacol 2007, 374:413-428

11. Yatomi Y, Ozaki Y, Ohmori T, Igarashi Y: Sphingosine 1-phosphate: synthesis and release. Prostaglandins Other Lipid Mediat 2001, 64:107-122

12. Pappu R, Schwab SR, Cornelissen I, Pereira JP, Regard JB, Xu Y, Camerer E, Zheng YW, Huang Y, Cyster JG, Coughlin SR: Promotion of lymphocyte egress into blood and lymph by distinct sources of sphingosine-1-phosphate. Science 2007, 316:295-298

13. Hanel $\mathrm{P}$, Andreani $\mathrm{P}$, Graler $\mathrm{MH}$ : Erythrocytes store and release sphingosine 1-phosphate in blood. FASEB J 2007, 21:1202-1209

14. Venkataraman K, Lee YM, Michaud J, Thangada S, Ai Y, Bonkovsky HL, Parikh NS, Habrukowich C, Hla T: Vascular endothelium as a contributor of plasma sphingosine 1-phosphate. Circ Res 2008, 102:669-676

15. Sanchez T, Hla T: Structural and functional characteristics of S1P receptors. J Cell Biochem 2004, 92:913-922

16. Hait NC, Allegood J, Maceyka M, Strub GM, Harikumar KB, Singh SK Luo C, Marmorstein R, Kordula T, Milstien S, Spiegel S: Regulation of histone acetylation in the nucleus by sphingosine-1-phosphate. Science 2009, 325:1254-1257

17. Bonder CS, Sun WY, Matthews T, Cassano C, Li X, Ramshaw HS, Pitson SM, Lopez AF, Coates PT, Proia RL, Vadas MA, Gamble JR: Sphingosine kinase regulates the rate of endothelial progenitor cell differentiation. Blood 2009, 113:2108-2117

18. Pitson SM, Xia P, Leclercq TM, Moretti PA, Zebol JR, Lynn HE Wattenberg BW, Vadas MA: Phosphorylation-dependent translocation of sphingosine kinase to the plasma membrane drives its oncogenic signalling. J Exp Med 2005, 201:49-54

19. Gamble JR, Sun WY, Li X, Hahn CN, Pitson SM, Vadas MA, Bonder CS: Sphingosine kinase-1 associates with integrin \{alpha\} $\{$ beta\}3 to mediate endothelial cell survival. Am J Pathol 2009, 175:2217-2225

20. Xia P, Gamble JR, Rye KA, Wang L, Hii CS, Cockerill P, Khew-Goodall $Y$, Bert AG, Barter PJ, Vadas MA: Tumor necrosis factor-alpha induces adhesion molecule expression through the sphingosine kinase pathway. Proc Natl Acad Sci USA 1998, 95:14196-14201

21. Kim I, Moon SO, Kim SH, Kim HJ, Koh YS, Koh GY: Vascular endothelial growth factor expression of intercellular adhesion molecule 1 (ICAM-1), vascular cell adhesion molecule 1 (VCAM-1), and E-selectin through nuclear factor-kappa B activation in endothelial cells. J Biol Chem 2001, 276:7614-7620

22. Faull RJ, Wang J, Leavesley DI, Puzon W, Russ GR, Vestweber D, Takada Y: A novel activating anti-beta1 integrin monoclonal antibody binds to the cysteine-rich repeats in the beta1 chain. J Biol Chem 1996, 271:25099-25106

23. Gamble JR, Matthias LJ, Meyer G, Kaur P, Russ G, Faull R, Berndt MC, Vadas MA: Regulation of in vitro capillary tube formation by anti-integrin antibodies. J Cell Biol 1993, 121:931-943 
24. Litwin M, Clark K, Noack L, Furze J, Berndt M, Albelda S, Vadas M, Gamble J: Novel cytokine-independent induction of endothelial adhesion molecules regulated by platelet/endothelial cell adhesion molecule (CD31). J Cell Biol 1997, 139:219-228

25. Pitson SM, D'Andrea RJ, Vandeleur L, Moretti PA, Xia P, Gamble JR, Vadas MA, Wattenberg BW: Human sphingosine kinase: purification, molecular cloning and characterization of the native and recombinant enzymes. Biochem J 350 Pt 2000, 2:429-441

26. Pitson SM, Moretti PA, Zebol JR, Xia P, Gamble JR, Vadas MA, D'Andrea RJ, Wattenberg BW. Expression of a catalytically inactive sphingosine kinase mutant blocks agonist-induced sphingosine kinase activation. A dominant-negative sphingosine kinase. J Biol Chem 2000, 275:33945-33950

27. Bonder CS, Clark SR, Norman MU, Johnson P, Kubes P: Use of CD44 by CD4+ Th1 and Th2 lymphocytes to roll and adhere. Blood 2006 , 107:4798-4806

28. Eggleton P, Gargan R, Fisher D: Rapid method for the isolation of neutrophils in high yield without the use of dextran or density gradient polymers. J Immunol Methods 1989, 121:105-113

29. Li X, Stankovic M, Bonder CS, Hahn CN, Parsons M, Pitson SM, Xia P, Proia RL, Vadas MA, Gamble JR: Basal and angiopoietin-1-mediated endothelial permeability is regulated by sphingosine kinase- 1 . Blood 2008, 111:3489-3497

30. Pitson SM, Moretti PA, Zebol JR, Lynn HE, Xia P, Vadas MA, Wattenberg BW: Activation of sphingosine kinase 1 by ERK1/2-mediated phosphorylation. EMBO J 2003, 22:5491-5500

31. Whetton AD, Lu Y, Pierce A, Carney L, Spooncer E: Lysophospholipids synergistically promote primitive hematopoietic cell chemotaxis via a mechanism involving Vav 1. Blood 2003, 102:2798-2802

32. Kim I, Kim JH, Ryu YS, Liu M, Koh GY: Tumor necrosis factor-alpha upregulates angiopoietin-2 in human umbilical vein endothelial cells. Biochem Biophys Res Commun 2000, 269:361-365

33. Carlson TR, Feng Y, Maisonpierre PC, Mrksich M, Morla AO: Direct cell adhesion to the angiopoietins mediated by integrins. J Biol Chem 2001, 276:26516-26525

34. Gares SL, Giannakopoulos N, MacNeil D, Faull RJ, Pilarski LM: During human thymic development, beta 1 integrins regulate adhesion, motility, and the outcome of RHAMM/hyaluronan engagement. J Leukoc Biol 1998, 64:781-790

35. Issekutz TB, Miyasaka M, Issekutz AC: Rat blood neutrophils express very late antigen 4 and it mediates migration to arthritic joint and dermal inflammation. J Exp Med 1996, 183:2175-2184

36. Burns JA, Issekutz TB, Yagita H, Issekutz AC: The alpha 4 beta 1 (very late antigen (VLA)-4, CD49d/CD29) and alpha 5 beta 1 (VLA-5, CD49e/CD29) integrins mediate beta 2 (CD11/CD18) integrin-independent neutrophil recruitment to endotoxin-induced lung inflammation. J Immunol 2001, 166:4644-4649

37. Gao JX, Issekutz AC: The beta 1 integrin, very late activation antigen-4 on human neutrophils can contribute to neutrophil migration through connective tissue fibroblast barriers. Immunology 1997 , 90:448-454

38. Pello OM, Duthey B, Garcia-Bernal D, Rodriguez-Frade JM, Stein JV, Teixido J, Martinez C, Mellado M: Opioids trigger alpha 5 beta 1 integrinmediated monocyte adhesion. J Immunol 2006, 176:1675-1685
39. Ley K, Laudanna C, Cybulsky MI, Nourshargh S: Getting to the site of inflammation: the leukocyte adhesion cascade updated. Nat Rev Immunol 2007, 7:678-689

40. Loike JD, Cao L, Budhu S, Marcantonio EE, El KJ, Hoffman S, Yednock TA, Silverstein SC: Differential regulation of beta1 integrins by chemoattractants regulates neutrophil migration through fibrin. J Cell Biol 1999, 144:1047-1056

41. Davis S, Aldrich TH, Jones PF, Acheson A, Compton DL, Jain V, Ryan TE, Bruno J, Radziejewski C, Maisonpierre PC, Yancopoulos GD: Isolation of angiopoietin-1, a ligand for the TIE2 receptor, by secretion-trap expression cloning. Cell 1996, 87:1161-1169

42. Maisonpierre PC, Suri C, Jones PF, Bartunkova S, Wiegand SJ, Radziejewski C, Compton D, McClain J, Aldrich TH, Papadopoulos N, Daly TJ, Davis S, Sato TN, Yancopoulos GD: Angiopoietin-2, a natural antagonist for Tie2 that disrupts in vivo angiogenesis. Science 1997, 277:55-60

43. Suri C, Jones PF, Patan S, Bartunkova S, Maisonpierre PC, Davis S, Sato TN, Yancopoulos GD: Requisite role of angiopoietin-1, a ligand for the TIE2 receptor, during embryonic angiogenesis. Cell 1996, 87:1171-1180

44. Gale NW, Thurston G, Davis S, Wiegand SJ, Holash J, Rudge JS, Yancopoulos GD: Complementary and coordinated roles of the VEGFs and angiopoietins during normal and pathologic vascular formation. Cold Spring Harb Symp Quant Biol 2002, 67:267-273

45. Fiedler U, Reiss Y, Scharpfenecker M, Grunow V, Koidl S, Thurston G Gale NW, Witzenrath M, Rosseau S, Suttorp N, Sobke A, Herrmann M, Preissner KT, Vajkoczy P, Augustin HG: Angiopoietin-2 sensitizes endothelial cells to TNF-alpha and has a crucial role in the induction of inflammation. Nat Med 2006, 12:235-239

46. Fiedler U, Scharpfenecker M, Koidl S, Hegen A, Grunow V, Schmidt JM, Kriz W, Thurston G, Augustin HG: The Tie-2 ligand angiopoietin-2 is stored in and rapidly released upon stimulation from endothelial cell Weibel-Palade bodies. Blood 2004, 103:4150-4156

47. Imanishi Y, Hu B, Jarzynka MJ, Guo P, Elishaev E, Bar-Joseph I, Cheng SY: Angiopoietin-2 stimulates breast cancer metastasis through the alpha(5)beta(1) integrin-mediated pathway. Cancer Res 2007, 67:4254-4263

48. Cascone I, Napione L, Maniero F, Serini G, Bussolino F: Stable interaction between alpha5beta1 integrin and Tie2 tyrosine kinase receptor regulates endothelial cell response to Ang-1. J Cell Biol 2005, 170:993-1004

49. Boujaoude LC, Bradshaw-Wilder C, Mao C, Cohn J, Ogretmen B, Hannun YA, Obeid LM: Cystic fibrosis transmembrane regulator regulates uptake of sphingoid base phosphates and lysophosphatidic acid: modulation of cellular activity of sphingosine 1-phosphate. J Biol Chem 2001, 276:35258-35264

50. Olivera A, Spiegel S: Sphingosine kinase: a mediator of vital cellular functions. Prostaglandins Other Lipid Mediat 2001, 64:123-134

51. Aoki S, Yatomi Y, Shimosawa T, Yamashita H, Kitayama J, Tsuno NH, Takahashi K, Ozaki Y: The suppressive effect of sphingosine 1-phosphate on monocyte-endothelium adhesion may be mediated by the rearrangement of the endothelial integrins alpha(5)beta(1) and alpha (v) beta(3). J Thromb Haemost 2007, 5:1292-1301 